\title{
Thermal Analysis of Sulfur and Selenium Compounds with Multiple Applications, Including Anticancer Drugs
}

\author{
Daniel Plano, Juan Antonio Palop and Carmen Sanmartín
}

Additional information is available at the end of the chapter

http://dx.doi.org/10.5772/53048

\section{Introduction}

Thermal methodologies are analytical and quantitative methods capable of providing reliable, fast and reproducible results. Thermogravimetry (TG), Differential Scanning Calorimetry (DSC) and Isothermal Titration Calorimetry (ITC) techniques are the chosen methods for several physicochemical determinations.

ITC is the most quantitative means available for measuring the thermodynamic properties of a protein-protein interaction. So, ITC is the calorimetric approach most used to investigate biomolecular interactions. ITC measures the binding equilibrium directly by determining the heat evolved on association of a ligand with its binding partner. In a single experiment, the values of the binding constant $\left(\mathrm{K}_{\mathrm{a}}\right)$, the stoichiometry $(\mathrm{n})$ and the enthalpy of binding $\left(\Delta H_{\mathrm{b}}\right)$ are determined. The free energy and entropy of binding are determined from the association constant. The temperature dependence of the $\Delta H_{\mathrm{b}}$ parameter, measured by performing the titration at varying temperatures, describes the $\Delta C_{\mathrm{p}}$ term. Furthermore, binding of proteins and small molecules to nucleic acids is of course critical to all organisms, playing a role in replication, transcription, translation and DNA repair processes to name just a few. Protein association with nucleic acids has therefore been the subject of much study throughout the years, and ITC has been one of the most common tools used for such investigations. When used in conjunction with complementary techniques such as X-ray crystallography, ITC can provide an informative thermodynamic account of these systems [1]. Besides, ITC is a useful technique in the protein-lipid interactions studies, and two examples in 2008 were the study of the effect of cholesterol on an amphibian antimicrobial peptide interaction with membranes [2], and analysis of the interaction of mammalian bonemarrow derived peptides with model and natural membranes [3]. Finally, ITC is a powerful tool for the pursuit of higher affinity drugs with improved binding specificities [4]. In its 
simplest form, ITC is a rapid and convenient method for measuring affinities of new leads and optimized compounds. In addition, however, ITC is particularly useful in providing information about the mode of binding. The use of ITC as a general tool in drug design and characterization is exemplified in a study by McKew et al. [5] who demonstrated the efficacy of ITC for studying three classes of inhibitor to the cytosolic amphitropic enzyme phospholipase A2 alpha (cPLA2a).

TG is mainly employed to study thermal stability, kinetic parameters and degradation processes for a wide range of materials. DSC allows characterizing protein stability and folding, drug-protein interactions, as well as heat capacity, vapor pressures and polymorphism. Moreover, it has been pointed out the usefulness of DSC technique as a potential tool for the early diagnosis, monitoring and screening of cancer patients [6].

\section{Application of thermal analysis to sulfur and selenium compounds with multiple applications}

Sulfur (S) and selenium (Se) compounds present several applications in a great variety of fields. We consider the anticancer activity of these compounds as the most important application due to the burden, costs and mortality rates caused by cancer disease. Thus, we will treat in depth the application of thermal techniques to these anticancer compounds in the following section.

Due to the vast applications of $S$ and Se compounds and to the great structural variability in each of these applications, the $S$ and Se compounds are going to be classified according to their structural features.

\subsection{Coordinated compounds}

The study of the degradation process is one of the most common utility for thermal techniques in the study of metal complex derivatives. Coordination compounds with dithiocarbamates have attracted attention because of their potential biological activity [7-10]. In 2006, a novel dithiocarbamate ligand L (triammonium- $N$-dithiocarboxyiminodiacetate) was synthesized and the thermal decomposition of its cooper (II), niquel (II) and palladium (II) was studied by DSC and thermogravimetry [11]. The authors showed that thermal stability of $\left(\mathrm{NH}_{4}\right)_{3} \mathrm{~L}$ is low and its decomposition starts with evaporation of an ammonia molecule. Of the three complexes, $\mathrm{Cu}\left(\mathrm{H}_{2} \mathrm{~L}\right)_{2}$ is the least thermally stable. Thermal decomposition of the complexes most likely begins with decarboxylation. It is endothermic up to $500 \mathrm{~K}$, but exothermic oxidation processes are observed above this temperature. Thermal decomposition of the cooper (II) complex is accompanied by its melting and with an exothermic structural rearrangement [11]. During the last two years, these thermal techniques have been used to study the stability and to characterize the degradation process of several dithiocarbamate complexes [12-14]. On the other hand, a study of the degradation process for three novel selenocyanato complexes has been published recently [15]. The authors demonstrated that all compounds decompose in a single heating step without the formation of ligand-deficient intermediates. 
Another application of thermal analysis is to study the chemical structure and the structure rearrangements in metallic complexes. The VA main group metal compounds including inorganic and metallorganic complex have showed interesting physical properties, medical and material functions. Some bismuth complexes can be used in medicine, microbiology and pharmacology [16-18]. Two studies with thiourea complexes of antimony and bismuth have evidenced several structure rearrangements or phase transformations for these complexes from 100 to $170{ }^{\circ} \mathrm{C}[19,20]$.

Several studies have been carried out in order to determine the specific and thermodynamic constants of methionine, which is one of the nine essential amino acids needed by human beings and contains a sulfur atom, and 2-mecaptonicotinic acid complexes [21, 22].

\subsection{Glass materials}

Chalcogenide semiconductors have been proposed for phase change nonvolatile random access memories, which is becoming the next generation for memory technology [23]. So, the proper description of thermal behavior of semiconducting chalcogenide glasses is crucial to understand their properties and functions. One of the crucial techniques to study the glass transition kinetics is the differential thermal analysis (DTA) and DSC.

Among the chalcogenide systems, selenium and selenium based glassy alloys have been intensively studied due to their wide technical applications, especially in the field of electronics and optoelectronics. A recent study has used the DTA technique to study the glass transition kinetics of the two binary Se-In alloys in comparison with that of pure Se. The glass transition temperature was found to be shifting to a higher value with increasing of heating rates and indium content. It was observed an increase of the stability parameters accompanied with the introduction of In into the Se matrix [24]. Another interesting Se based glassy alloys are Se-Sb alloys owing to their electrical, optical dielectric and thermal properties. Mehta et al. have reported the thermal characterization with calorimetric measurements for some Se-Sb alloys [25]. They reported the Hruby number, which is the strong indicator of glass forming tendency, thermal stability parameter and the values of crystallization enthalpy and entropy.

Selenium-tellurium thin films have attractive semiconductors for device application. Se-Te form a continuous series of solid solution and the Se-Te system has an intermediate behavior between pure Se and pure Te. The addition of Te has a catalytic effect on the crystallization of Se. In 2009, the crystallization parameters of the bulk Se-Te chalcogenide glass have been studied using DSC [26]. The values of glass transition temperature, onset crystallization temperature, peak crystallization temperature and enthalpy released with and without laser irradiation for different exposure time have been studied. The films showed indirect allowed interband transition that is influenced by the laser irradiation.

Ternary systems of chalcogenide glasses containing metal elements possess unique optical, electrical and physicochemical properties [27]. The most popular metal is silver and its addition into chalcogenide glasses leads to a drastic change in the physical and chemical 
properties of the material, for instance, it increases the conductivity by several orders of magnitude and decreases the slope of frequency dependence of alternating current (AC) conductivity. A study conducted by Ogusu et al. carried out DSC, X-ray diffraction (XRD)

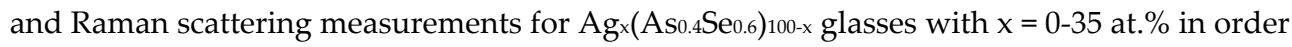
to investigate the crystallization kinetics and the local structure [28]. The DSC curves of the samples with Ag content $x=15-35$ at. $\%$ were obtained at various heating rates for different $\mathrm{Ag}$ contents and two or three exothermic peaks for the crystallization were found depending on the Ag content. Furthermore, the dimension of crystal growth of sample particles and activation energy were determined using Matusita's equation to analyze the DSC data. It was found that the surface and bulk crystallization take place depending on the Ag content and peak crystallization temperatures [28].

Glassy selenium has low sensitivity and thermal instability. These properties can be improved by alloying of some elements into selenium matrix, such as arsenic [29] and antimony [30,31]. The proper description of thermal behavior of these glasses is important for understanding their properties and applications. Recently, the thermal properties and structure of AsxSe100-x and SbxSe100-x glass-forming systems $(x=0,1,2,4,8$ and 16) were reported by conventional and StepScan DSC and Raman spectroscopy [32]. Among these thermal properties, the authors studied the glass transition temperature and the crystallization of undercooled melts. So, the glass transition temperature for AsxSe100-x system increases almost linearly with increasing As content from 40 up to $93{ }^{\circ} \mathrm{C}$, because the glass structure becomes more stable due to cross-linking of Se chains by As. Nevertheless, the glass transition temperature of $\mathrm{Sb} \times \mathrm{Se} 100-x$ changes only slightly from 40 to $48{ }^{\circ} \mathrm{C}$ [32]. Concerning to the study of crystallization of undercooled melts, it was found that only selenium crystallizes from undercooled melts of As-Se system and its tendency to crystallize decreases markedly with increasing As content, for arsenic content higher than 4 at.\% no crystallization was observed. In the case of $\mathrm{Sb}$-Se system $\mathrm{Sb}_{2} \mathrm{Se}_{3}$ crystallizes in the first step followed by trigonal selenium crystallization from non-stoichiometric undercooled melt [32].

Another technologically important ternary system of chalcogen elements are the infrared transmitting glasses based on Ge-Sb-Se because they are good transmitters of radiation in the 2-16 $\mu \mathrm{m}$ wavelength region. The applications include fabrication of optical components like IR lenses, windows and filter used in thermal imaging systems. The Sb-Ge-Se films result sensitive for the UV exhibit mechanical, optical and structural changes [33, 34]. An understanding of the glass forming tendency and crystallization kinetics in these chalcogenide materials is very important to develop them for applications based on the amorphous to crystallization phase change and vice versa. So, one report evaluated the glass-forming ability of some alloys in $\mathrm{Sb}_{\mathrm{x}} \mathrm{Ge}_{25-\mathrm{x}} \mathrm{Se}_{75}(0 \leq \mathrm{x} \leq 10)$ system by using various thermal stability criteria, based on characteristic temperatures [35]. It was observed that the thermal stability decrease with increasing Sb content in the glassy system.

\subsection{Inorganic mixtures}

Several reports have been published concerning to the solubility and thermal characterization of various metal-selenite systems. For example, some manganese(II) 
selenite are used for coloring glasses, enamel and glazes. On the basis of $\mathrm{MnSeO}_{3}$, two manganese selenides ( $\alpha$-MnSe and $\left.\mathrm{MnSe}_{2}\right)$ were obtained having very interesting semiconductor properties [36]. Vlaev et al. have studied the crystallization fields of manganese(II) selenites in the system $\mathrm{MnSeO}_{3}-\mathrm{SeO}_{2}-\mathrm{H}_{2} \mathrm{O}$ in the temperature interval 25-300 ${ }^{\circ} \mathrm{C}$ and characterized the observed phases [37]. Previously to this article, the same author reported the crystallization fields and the characterization of the observed phases for the system $\mathrm{NiSeO}_{3}-\mathrm{SeO}_{2}-\mathrm{H}_{2} \mathrm{O}$ [38]. Another article studied the phase equilibrium in the system $\mathrm{CdO}-\mathrm{SeO}_{2}-\mathrm{H}_{2} \mathrm{O}$ at 25 and $100^{\circ} \mathrm{C}$ and the thermolysis mechanism of the compounds obtained.

The ytterbium selenites can serve as initial substances for obtaining selenides and oxyselenides having valuable photoconductive and superconductive properties. So, Gospodinov et al. have studied the solubility isotherm of the three-component system $\mathrm{Yb}_{2} \mathrm{O}_{3}-\mathrm{SeO}_{2}-\mathrm{H}_{2} \mathrm{O}$ at $100{ }^{\circ} \mathrm{C}$ [39]. Furthermore, they have performed simultaneous TG and DTA curves of the compounds obtained in its fields of crystallization and the mechanism of the thermal decomposition [39].

Alkali metal sulfates, selenite and phosphate tellurate compounds having the formula $\mathrm{M}_{2} \mathrm{XO}_{4} \mathrm{Te}(\mathrm{OH})_{6}$, where $\mathrm{M}$ is the metal and $\mathrm{X}$ is $\mathrm{S}$, Se or $\mathrm{P}$, form a broad families with interesting properties, such as superprotonic conduction and ferroelectricity [40-42]. So, synthesis, calorimetric and conductivity studies of new mixed solution of rubidium sulfate selenate tellurate [43] and thallium selenate tellurate [44] have been carried out.

\subsection{Miscellaneous compounds}

In the last two years, several thermal and structural investigations on crystal structures with thiourea have been carried out. The thermal decomposition of crystal structures with bisthiourea derivatives has been studied by TG-DSC [45]. Another study reported the growth and characterization of a new non-linear organometallic crystal (potassium thiourea thiocyanide or PTT) [46]. The TG curve showed the complete decomposition of PTT between 176 and $1000{ }^{\circ} \mathrm{C}$ in three steps with corresponding three DTA peaks.

Some selenoesters present promising photophysical properties for optical device applications such as emissive liquid crystal displays (LCDs), polarized organic lasers and anisotropic Light-emitting diodes (LEDs). Rampon et al. have reported the synthesis and the study of the liquid crystalline and fluorescent properties of novel selenoesters [47]. So, these compounds were fluorescent in the blue region and exhibited their stability and liquid crystalline properties over a large range of temperatures. Moreover, these compounds showed a rich phase polymorphism.

Cooper chalcogenides are considered as promising in electronic technology due to their physicochemical properties [48, 49]. Chrissofis et al. [50] have reported the thermal behavior of samples with very slight divergence from stoichiometry ( $\left.\mathrm{Cu}_{2-\mathrm{x}} \mathrm{Se}\right)$. Also, they have studied the nature of the transformation with non-isothermal measurements at different heating and cooling rates. 
Oligothiophenes and polythiophenes are another sulfur compounds that have attracted much attention due to their unusual electric and nonlinear optical properties as interesting materials for organic electronics and optoelectronics, LEDs, field-effect transistors, thin-film transistors... So, the relative stabilities of 2,2'- and 3,3'-bithiophenes (the main building blocks of these conducting organic materials) have been evaluated by experimental thermochemistry [51].

\section{Application of thermal analysis to sulfur and selenium compounds with anticancer activity}

In the last decade, among the wide range of compounds tested as potential anticancer agents, several structurally diverse derivatives that contain a sulfur or selenium template have been reported and have generated growing interest. For that reason, in this chapter we have focused on some relevant thermal studies in sulfur and selenium compounds with anticancer activity.

\subsection{Sulfur amino acids and cysteine cathepsins.}

The human family of cysteine cathepsins are a family of lysosomal proteases and has 11 members (cysteine cathepsin B, C, F, H, K, L, O, S, V, W and X), which share a conserved active site that is formed by cysteine, histidine and asparagine residues. Cysteine cathepsins are often upregulated in various human cancers, and have been implicated in distinct tumorigenic processes such as angiogenesis, proliferation, apoptosis and invasion. During cancer progression, cathepsins are often translocated to the cell surface of tumor cells or are secreted into the extracellular milieu, where they can promote tumor invasion through several possible mechanisms. Causal roles for cysteine cathepsins in cancer have been demonstrated by pharmacological and genetic techniques. This includes functional downregulation of cysteine cathepsin activity by increasing expression of endogenous inhibitors and administration of small-molecule cysteine protease inhibitors. Besides, causal roles for specific cysteine cathepsins in cancer have been demonstrated by downregulating their expression or crossing mouse models of cancer with mice in which the cysteine cathepsin has been genetically ablated. These studies have identified roles for cysteine cathepsins in both tumor cells and tumor-associated cells such as endothelial cells and macrophages.

Taking into account the causal roles for cysteine cathepsins, which present a cysteine residue in the active site, in cancer and the fact that the thiol-disulfide interchange reaction is important to a number of subjects in biochemistry, thermodynamic data regarding the relative energetics of the thiol and disulfide functional groups is essential for the understanding of the driving force and mechanism of biochemical processes. Temperatureinduced changes in crystalline amino acids are of interest for their properties and because they reveal the intrinsic motions of these structural fragments and their contribution to the dynamic properties of proteins.

So, a thermophysical study of the sulfur containing amino acids $L$-cysteine and $L$-cystine by DSC has been reported [52]. Heat capacities of both compounds were measured in the temperature interval from $\mathrm{T}=268 \mathrm{~K}$ to near their respective melting temperatures. 
Furthermore, a solid-solid phase transition close to the melting point is only observed in the L-cysteine. Additionally, several polymorphic forms have been reported for both compounds. $L$-cysteine crystallizes in the monoclinic and orthorhombic forms and has been structurally characterized [53,54]. Phase transitions have been detected when lowering the temperatures [55] and also when decreasing pressures up to $4.2 \mathrm{GPa}$ and decreasing to 1-7 GPa [56]. L-cystine crystallizes in the tetragonal and hexagonal forms and has also been studied at ambient $[57,58]$ and at low temperature [59] and at high pressures although no solid-solid phase transition has been detected.

\subsection{Metal complexes of sulfur compounds}

During the past decade the study of mixed sulfur donor ligand complexes with main group metals has made a progressive development due to the development of new analytical and structural techniques [60-62]. These complexes present potential applications in areas such as fast ion conductivity, photocatalysis and electro-optics, among others as well as several biochemical applications [63-65].

One of these promising complexes is antimony(III) bis(pyrrolidinedithiocarbamato) alkyldithiocarbonates. The link of two active ligands was the rational design used for the design of these complexes. So, pyrrolidine dithiocarbamates which represent a class of antioxidants mediate a wide variety of effects in biological systems[66]. It is a multipotent synthetic compound well known for its metal chelation property and one of the most potent and specific NF-kB inhibitor [67]. Besides, antimony metal containing compounds are commonly used to treat parasitic infections and exhibit a broad spectrum of chemotherapeutic applications and cytotoxic activities. So, a study has reported the synthesis, spectroscopic, thermal and structural behavior of antimony(III) bis(pyrrolidinedithiocarbamato)alkyldithiocarbonates [12]. Thermogravimetric studies not only allows to determine purity and thermal stability of the complex but also composition of the complex as well which it is observed during different steps of weight losses as a fragment formed in different temperature ranges [12].

Another type of complexes with a potent anticancer activity which were designed using the link of two active ligands, are the palladium (II) and platinum (IV) complexes with active sulfur ligands. The use of antitumor drugs based on platinum(II) metal complexes, cisplatin and its analogues carboplatin and oxaliplatin is limited by two factors: installation of tumor drug resistance and severe adverse effects [68, 69]. Therapeutic strategies are oriented towards the development of new platinum- and non-platinum-based antitumor drugs with higher efficiency, reduced general toxicity and broader spectrum of activity [70]. Sulfurcontaining molecules are studied as chemoprotectors in platinum-based chemotherapy. Dithiocarbamates have attracted particular attention for the use of chemical modulation of cisplatin nephrotoxicity [71-73].

The thermal behaviour of $\mathrm{Pd}(\mathrm{II})$ complexes with some dithiocarbamate derivatives was studied in order to establish the coordination mode of the ligand, to test the thermal stability [11] or to understand the effect of the alkyl chain attached to the nitrogen atom over the 
thermochemical parameters of the complexes [74, 75]. A series of $\mathrm{Pd}(\mathrm{II})$ complexes with tertbutylsarcosinedithiocarbamate [76], ethylsarcosinedithiocarbamate and 2-/3-picoline [77], dithiocarbamates and various amines [78] were developed as antitumor agents with low nephrotoxicity. Thermogravimetric analysis was used for the characterization of these compounds. Taking into accounts the kinetic inertness, high activity, low toxicity and suitability for oral administration of $\mathrm{Pt}(\mathrm{IV})$ complexes, some $\mathrm{Pt}(\mathrm{IV})$ complexes with dithiocarbamates have been synthesized. Morpholine dithiocarbamate, aniline dithiocarbamate and N-(methyl, cyclohexyl) dithiocarbamate alone [79] or with triphenyl phosphine as second ligand [80] were used in order to obtain $\mathrm{Pt}(\mathrm{IV})$ complexes with antitumour activity.

In 2012, Uivarosi et al. have reported the thermal and spectral studies of palladium(II) and platinum(IV) complexes with bis(dimethylthiocarbamoyl)sulphide and bis(diethylthiocarbamoyl)disulphide [81]. TG experiments revealed the nature of complex species as hydrated or anhydrous. Thermal decomposition of coordinated organic ligands occurs in one or two exothermic stages, the final residue being in all cases the free metal (Pd or Pt).

Other complexes with anticancer activity are de ruthenium (III) complexes with sulfur ligands. Ruthenium complexes with dimethyl sulfoxide (dmso) showed selective antitumor properties in preclinical testing [82]. Biological studies in cis- and trans-RuX $\left(\mathrm{dmso}_{4}\right.$ complexes $(\mathrm{X}=\mathrm{Cl}$ and $\mathrm{Br})$ refer to different tumor toxicity and anti-metastasis properties of the isomers [83]. Dmso can be coordinated to ruthenium as a metal center either through the sulfur (dmso-S) or through the oxygen atom (dmso-O). Dmso provides a moderate acceptor site for $\pi$-electron donors and bound through sulfur stabilizes ruthenium in lower $\mathrm{Ru}(\mathrm{II})$ oxidation state, more reactive toward tumor cells [84]. The biological activity of complexes can be modified by addition or change of the ligands. Phenothiazines and their N-alkyl derivatives are themselves biological active compounds, suitable to take part in complex formation. Moreover, they exhibit a strong in vitro antitumor activity in numerous and various tumor cell lines [85].

Recently, thermal decomposition of chlorpromazine hydrochloride ( $\mathrm{CP} \cdot \mathrm{HCl})$, trifluoperazine dihydrochloride $(\mathrm{TF} \cdot 2 \mathrm{HCl})$ and thioridazine hydrochloride $(\mathrm{TR} \cdot \mathrm{HCl})$, and the ruthenium complexes with dimethyl sulfoxide (dmso) of composition $\left[\mathrm{RuCl}_{2}(\mathrm{dmso})_{4}\right]$ and $\mathrm{L}\left[\mathrm{RuCl}_{3}(\mathrm{dmso})_{3}\right] \cdot x \mathrm{EtOH}, \mathrm{L}=\mathrm{CP} \cdot \mathrm{HCl}, \mathrm{TF} \cdot 2 \mathrm{HCl}$ or $\mathrm{TR} \cdot \mathrm{HCl}$ is described [86]. The phenothiazines are stable to temperature range of $200-280{ }^{\circ} \mathrm{C}$ with an increasing stability order of $\mathrm{TF} \cdot 2 \mathrm{HCl}<\mathrm{CP} \cdot \mathrm{HCl}<\mathrm{TR} \cdot \mathrm{HCl}$. The decomposition of all the compounds takes place in superposing steps.

\subsection{Alkylimidothio- and alkylimidoselenocarbamates}

During the last five years, our research group reported the promising and potent anticancer effects for several alkylimidothio- and alkylimidoselenocarbamate derivatives [87-89]. These compounds showed a remarkable cytotoxic activity in vitro against prostate cancer cells and other several cancer cell lines. One of these derivatives, the quinoline imidoselenocarbamate 
EI201, inhibits the PI3K/AKT/mTOR pathway, which is persistently activated and contributes to malignant progression in various cancers, and contributes to the loss of maintenance of the selfrenewal and tumorigenic capacity of cancer stem cells. This compound (EI201) suppressed almost $80 \%$ prostate tumor growth in vivo $(p<0.01)$ compared to controls at a relatively low dose $(10 \mathrm{mg} / \mathrm{kg})$ in a mouse xenograft model [90].

Degradation and fusion temperatures for 20 of these anticancer derivatives were determined using TG and DSC [91]. Analysis of the thermal data indicated that: (a) in general, sulfur compounds are more stable than selenium compounds; (b) the pyridine ring diminished stability of sulfur and selenium compounds much more than the carbocyclic aromatic rings did; (c) selenomethyl derivatives are more stable than selenoethyl and selenoisopropyl compounds; (d) a chlorine atom on selenocompounds has surprising effects. So, the presence of intermolecular bonds was pointed out between chlorine atom and selenium atom [91]. With regard some substituents present on aromating ring and the ramification and length of chain, it can be concluded that the presence of electron-withdrawing groups in selenocompound structures improves their stability. Besides, selenomethyl derivatives are more stable than selenoethyl and selenoisopropyl compounds [91].

The determination of the polymorphism of a substance is of great importance due to the strong influence of the crystalline form on the physicochemical properties, bioavailability and stability of drugs [92], and, in some compounds with biological activity, can even become metastable forms, being twice as active as the stable form [93]. So, our research group has carried out the study of the physicochemical properties of polymorphic forms of a serie of alkylimidothio- and alkylimidoselenocarbamate derivatives with a combination of DSC, thermomicroscopy and X-ray diffractometry [94]. In this study we observed that polymorphs could be formed when the compounds are heated above their melting points. The results showed that there are four types of thermal behavior for alkylimidothio- and alkylmidoselenocarbamate derivatives: (a) compounds which do not evidence any polymorphic forms (behavior I); (b) compounds which solidify into an amorphous solid form (behavior II); (c) compounds which present a new polymorphic form at a Tonset lower than the original one (behavior III); (d) finally, compounds which have three polymorphic forms with three different Tonset values (behavior IV). Calorimetric studies demonstrated that sulfur and selenium analogs have the same thermal behavior. So, the different thermal behaviors observed for these alkylimidothio- and alkylimidoselenocarbamates are caused by the substituent groups in the aromatic ring, although there is no relationship between electron-withdrawing and electron-donating groups and the thermal behavior.

\subsection{Case study: Thermal analysis of selenyl acetic derivatives.}

In 2009, our research group reported the cytotoxic and antiproliferative activities in vitro of selenyl acetic derivatives against several cancer cell lines [95]. Considering the structure of these derivatives and their inefficacy to induce apoptosis and to affect to cell cycle, we decided to perform a thermal analysis for these derivatives. So, we carried out a thermal stability and calorimetric studies for some of these anticancer selenyl acetic acids (Figure 1). 
<smiles>CC(Cc1ccccc1)SCC(=O)O</smiles>

Compound 1: $\mathrm{R}=2-\mathrm{Cl}$;

Compound 2: $\mathrm{R}=\mathrm{H}$;

Compound 3: $\mathrm{R}=3,5-\mathrm{diOCH}_{3}$

Compound 4: $\mathrm{R}=4-\mathrm{CF}_{3}$;

Compound 5: $\mathrm{R}=4-\mathrm{CN}$

Compound 6: $\mathrm{R}=4-\mathrm{CH}_{3}$;

Compound 7: $\mathrm{R}=\mathrm{H}$;

Compound 8: $\mathrm{R}=$ Phenyl;
$\mathrm{X}=\mathrm{N} ; \mathrm{n}=0$

$\mathrm{X}=\mathrm{C} ; \mathrm{n}=0$

$\mathrm{X}=\mathrm{C} ; \mathrm{n}=0$

$\mathrm{X}=\mathrm{C} ; \mathrm{n}=0$

$\mathrm{X}=\mathrm{C} ; \mathrm{n}=0$

$\mathrm{X}=\mathrm{C} ; \mathrm{n}=0$

$\mathrm{X}=\mathrm{C} ; \mathrm{n}=1$

$\mathrm{X}=\mathrm{C} ; \mathrm{n}=0$

Figure 1. General structure for studied selenyl acetic acids.

\subsubsection{Thermal stability studies}

The thermogravimetric studies were carried out with a Perkin-Elmer TGA-7. The thermobalance was calibrated with alumel and nickel at $10{ }^{\circ} \mathrm{C} \mathrm{min}^{-1}$. The calibration of the oven temperatures was carried out automatically. Mass calibration was carried out with a certified mass of $10 \mathrm{mg}$ (ASTM E617).

The calorimeter was calibrated with indium and zinc (provided by Perkin-Elmer and fabricated according to guideline ISO35) at $10{ }^{\circ} \mathrm{C} \mathrm{min}-1$ and a nitrogen flow of $20 \mathrm{~mL} \mathrm{~min}{ }^{-1}$. The gases connected to the equipment were nitrogen and air with a purity of $99.999 \%$.

Thermogravimetric analyses were carried out under nitrogen atmosphere with a gas flow of

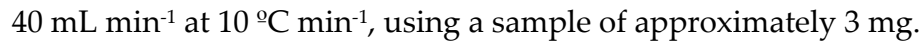

All the compounds sublimated before the degradation process start. So, it is not possible to study the thermal stability of these compounds using thermogravimetric techniques.

\subsubsection{Calorimetric studies}

The calorimetric studies were carried out with a Perkin-Elmer DSC Diamond. Calorimetric analyses were carried out in aluminium capsules for volatiles of $10 \mu \mathrm{L}$, at a heating rate of 10 ${ }^{\circ} \mathrm{C} \mathrm{min}^{-1}$, using a sample of approximately $3 \mathrm{mg}$, in order to establish the Tonset and the enthalpy of fusion $\Delta H_{f}$. All of the experiments were performed at least three times and the values were expressed as mean \pm standard deviation.

The obtained data (Table 1) allow us to point out the following calorimetric behaviors:

1. Regarding to the Tonset values:

a. The substitution on the aromatic ring causes an increase in the fusion temperatures of these compounds.

b. The inclusion of a methylene group between aromatic ring and carbonyl group seem to lead to a diminution in the Tonset values.

c. The presence of groups such as cyano and chloro on the ring, which can form hydrogen bonds, significantly increase the fusion temperatures of these derivatives.

2. Regarding to the enthalpy of fusion values: 
a. Compounds with phenyl ring ( 2 and 7 ) possess values for enthalpy of fusion higher than Tonset ones. It could be caused by the presence of strong $\pi-\pi$ stacking interactions between two molecules in the crystal packaging.

b. Compounds with groups that can establish hydrogen interactions, such as $\mathrm{CN}$ and $\mathrm{Cl}$, substituted over the ring present the highest enthalpy values, owing to these hydrogen interactions.

c. The substitution on the para position of the phenyl ring with groups that cannot establish hydrogen interactions significantly diminished the enthalpy values. It seems that these substituents alter the electronic distribution over the ring, affecting to the $\pi-\pi$ stacking interactions strength.

\begin{tabular}{lll}
\hline Reference & Tonset $^{\left({ }^{\mathbf{o}} \mathrm{C} \pm \mathrm{SD}\right)}$ & $\Delta \boldsymbol{H}_{f}\left(\mathrm{Jg}^{-1}\right)$ \\
\hline Compound 1 & $157.2 \pm 0.2$ & $126.8 \pm 4.8$ \\
Compound 2 & $83.3 \pm 0.6$ & $92.3 \pm 2.2$ \\
Compound 3 & $117.4 \pm 0.3$ & $108.3 \pm 5.5$ \\
Compound 4 & $107.7 \pm 1.1$ & $73.7 \pm 1.0$ \\
Compound 5 & $146.5 \pm 0.1$ & $112.3 \pm 1.7$ \\
Compound 6 & $92.2 \pm 0.2$ & $78.7 \pm 0.8$ \\
Compound 7 & $73.8 \pm 0.3$ & $74.9 \pm 7.2$ \\
Compound 8 & $130.1 \pm 0.4$ & $105.9 \pm 4.6$ \\
\hline
\end{tabular}

Table 1. Tonset and enthalpy of fusion values for selenyl acetic acid derivatives studied.

The calorimetric data (Table 1) demonstrated that compounds 1 and 5 present a very significant higher Tonset value for the fusion process than the other selenyl acetic derivatives. Both compounds present two groups substituted in the para position of the aromatic ring that can act as hydrogen bonding donors. So, these groups could form a different hydrogen bond interaction with the proton of carboxylic acid group (Figure 2) and this interaction should be stronger than the interactions established in the rest of the compounds.

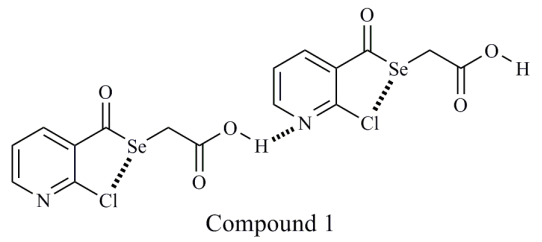<smiles>N#Cc1ccc(C(=O)CSCC(=O)O[In]N=Cc2ccc(C(=O)[Se]CC(=O)O)cc2)cc1</smiles>

Figure 2. Possible interactions in the crystal packaging for compounds 1 and 5.

If we compare the calorimetric data for selenyl acetic derivatives with other organoselenium compounds (alkylimidoselenocarbamates) synthesized and published by our research group [91], we observed that the Tonset values for the first ones were significantly lower that their imidoselenocarbamate analogs (Table 2). The selenyl acetic derivatives are smaller molecules than imidoselenocarbamates and hence they possess lower $T_{\text {onset values. }}$ Nevertheless, the enthalpy of fusion values for selenyl acetic acids are significantly higher 
compared with the imidoselenocarbamates in all cases (Table 2). These data seem to point to the existence of intramolecular hydrogen bonds for selenyl acetic derivatives (Figure 3).

\begin{tabular}{|c|c|c|c|c|c|c|c|}
\hline \multirow[b]{2}{*}{ Ref. } & \multirow[b]{2}{*}{$\mathbf{R}$} & \multirow[b]{2}{*}{$X$} & \multirow[b]{2}{*}{$\mathbf{n}$} & \multicolumn{2}{|c|}{ Selenyl acetic acids } & \multicolumn{2}{|c|}{ Imidoselenocarbamates } \\
\hline & & & & $\begin{array}{c}\text { Tonset } \\
\left({ }^{\circ} \mathrm{C} \pm \mathrm{SD}\right)\end{array}$ & $\Delta H_{f}\left(\mathrm{Jg}^{-1}\right)$ & $\begin{array}{c}\text { Tonset } \\
\left({ }^{\circ} \mathrm{C} \pm \mathrm{SD}\right)\end{array}$ & $\Delta H_{f}\left(\mathrm{Jg}^{-1}\right)$ \\
\hline 1 & $2-\mathrm{Cl}$ & $\mathrm{N}$ & 0 & $157.2 \pm 0.2$ & $126.8 \pm 4.8$ & $186.8 \pm 0.2$ & $42.4 \pm 1.3$ \\
\hline 2 & $\mathrm{H}$ & $\mathrm{C}$ & 0 & $83.3 \pm 0.6$ & $92.3 \pm 2.2$ & $139.5 \pm 0.2$ & $30.6 \pm 0.6$ \\
\hline 3 & 3,5- $\mathrm{diOCH}_{3}$ & $\mathrm{C}$ & 0 & $117.4 \pm 0.3$ & $108.3 \pm 5.5$ & $163.6 \pm 0.3$ & $39.6 \pm 0.3$ \\
\hline 4 & $4-\mathrm{CF}_{3}$ & $\mathrm{C}$ & 0 & $107.7 \pm 1.1$ & $73.7 \pm 1.0$ & $172.9 \pm 0.3$ & $30.7 \pm 0.8$ \\
\hline 5 & $4-\mathrm{CN}$ & $\mathrm{C}$ & 0 & $146.5 \pm 0.1$ & $112.3 \pm 1.7$ & $219.5 \pm 2.8$ & $44.4 \pm 14.3$ \\
\hline 6 & $4-\mathrm{CH}_{3}$ & $\mathrm{C}$ & 0 & $92.2 \pm 0.2$ & $78.7 \pm 0.8$ & $148.5 \pm 0.3$ & $32.7 \pm 4.9$ \\
\hline 7 & $\mathrm{H}$ & $\mathrm{C}$ & 1 & $73.8 \pm 0.3$ & $74.9 \pm 7.2$ & --- & --- \\
\hline 8 & Phenyl & $\mathrm{C}$ & 0 & $130.1 \pm 0.4$ & $105.9 \pm 4.6$ & --- & --- \\
\hline
\end{tabular}

Table 2. Tonset and enthalpy of fusion values for selenyl acetic acids and imidoselenocarbamates.

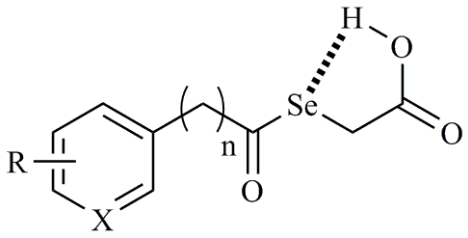

Figure 3. Intramolecular hydrogen bonds for selenyl acetic derivatives.

\section{Conclusions}

Sulfur (S) and selenium (Se) compounds present several applications in a great variety of fields and the study of their thermal behavior is important for their usefulness in these applications. So, the thermal data are necessary to understand the properties and functions for most of these derivatives. The application of the thermal techniques to these $\mathrm{S}$ and Se compounds allows, among others: (a) the study of degradation process, as well as the quantification of the purity and composition for coordination compounds; (b) the characterization of thermal behavior for semiconducting glasses; (c) the determination of solubility isotherms and the field of crystallization of inorganic metal-selenite mixtures.

In the last decade, among the wide range of compounds tested as potential anticancer agents, several structurally diverse derivatives that contain a sulfur or selenium template have been reported and have generated growing interest. For that reason, in this chapter we have focused on some relevant thermal studies in sulfur and selenium compounds with anticancer activity. The thermal techniques, and particularly the DSC, are especially useful 
in these compounds since they can point out future issues in its pharmaceutical development. The determination of the polymorphism of a substance is of great importance due to the strong influence of the crystalline form on the physicochemical properties, bioavailability and stability of drug, and, in some compounds with biological activity, can even become metastable forms, being twice as active as the stable form.

Finally, we report the unpublished thermal analysis data for eight selenyl acetic acid derivatives, which possess cytotoxic activity in vitro against several cancer cell lines. All the compounds sublimated before the degradation process start. So, it is not possible to study the thermal stability of these compounds using thermogravimetric techniques. Nevertheless, the obtained results for calorimetric studies allow to point out some calorimetric behaviors concerning to their stability in the fusion process: (a) the substitution on the aromatic ring causes an increase in the fusion temperatures of these compounds; (b) the inclusion of a methylene group between aromatic ring and carbonyl group seem to lead to a diminution in the Tonset values; (c) the presence of groups such as cyano and chloro on the ring, which can form hydrogen bonds, significantly increase the fusion temperatures of these derivatives.

\section{Author details}

Daniel Plano*

Synthesis Section, Department of Organic and Pharmaceutical Chemistry, University of Navarra, Pamplona, Spain

Department of Pharmacology, Penn State Hershey College of Medicine, Hershey, PA, USA

Juan Antonio Palop and Carmen Sanmartín

Synthesis Section, Department of Organic and Pharmaceutical Chemistry, University of Navarra, Pamplona, Spain

\section{References}

[1] Zhou Y Z, Larson J D, Bottoms C A, Arturo E C, Henzl M T, Jenkins J L, Nix J C, Becker D F, Tanner J J (2008) Structural Basis of the Transcriptional Regulation of the Proline Utilization Regulon by Multifunctional PutA. Journal of Molecular Biology. 381: 174188.

[2] Verly R M, Rodrigues M A, Daghastanli K R P, Denadai A M L, Cuccovia I M, Bloch C, Frezard F, Santoro M M, Pilo-Veloso D, Bemquerer M P (2008) Effect of Cholesterol on the Interaction of the Amphibian Antimicrobial Peptide DD K with Liposomes. Peptides. 29: 15-24.

[3] Andrushchenko V V, Aarabi M H, Nguyen L T, Prenner E J, Vogel H J (2008) Thermodynamics of the Interactions of Tryptophan-Rich Cathelicidin Antimicrobial Peptides with Model and Natural Membranes. Biochimica Et Biophysica ActaBiomembranes. 1778: 1004-1014.

\footnotetext{
${ }^{*}$ Corresponding Author
} 
[4] Chaires J B. In Annual Review of Biophysics, 2008; Vol. 37, pp 135-151.

[5] McKew J C, Lee K L, Shen M W H, Thakker P, Foley M A, Behnke M L, Hu B, Sum F W, Tam S, Hu Y, Chen L, Kirincich S J, Michalak R, Thomason J, Ipek M, Wu K, Wooder L, Ramarao M K, Murphy E A, Goodwin D G, Albert L, Xu X, Donahue F, Ku M S, Keith J, Nickerson-Nutter C L, Abraham W M, Williams C, Hegen M, Clark J D (2008) Indole Cytosolic Phospholipase a(2) Alpha Inhibitors: Discovery and in Vitro and in Vivo Characterization of 4-\{3-5-Chloro-2-(2-\{(3,4-dichlorobenzyl)sulfonyl amino\}ethyl)-1(diphenylmethyl)-1H-indol-3-yl propyl\}benzoic Acid, Efipladib. Journal of Medicinal Chemistry. 51: 3388-3413.

[6] Garbett N C, Mekmaysy C S, Helm C W, Jenson A B, Chaires J B (2009) Differential Scanning Calorimetry of Blood Plasma for Clinical Diagnosis and Monitoring. Experimental and Molecular Pathology. 86: 186-191.

[7] Manoussakis G, Bolos C, Ecateriniadou L, Sarris C (1987) Synthesis, Characterization and Anti-Bacterial Studies of Mixed-Ligand Complexes of DithiocarbamatoThiocyanato and Iron(III), Nickel(II), Copper(II) and Zinc(II). European Journal of Medicinal Chemistry. 22: 421-425.

[8] Montagner D, Marzano C, Gandin V (2011) Synthesis, Characterization and Cytotoxic Activity of Palladium (II) dithiocarbamate Complexes with Alpha,Omega-Diamines. Inorganica Chimica Acta. 376: 574-580.

[9] Chen Y-W, Chen K-L, Chen C-H, Wu H-C, Su C-C, Wu C-C, Way T-D, Hung D-Z, Yen C-C, Yang Y-T, Lu T-H (2010) Pyrrolidine Dithiocarbamate (PDTC)/Cu Complex Induces Lung Epithelial Cell Apoptosis through Mitochondria and ER-Stress Pathways. Toxicology Letters. 199: 333-340.

[10] Mohamed G G, Ibrahim N A, Attia H A E (2009) Synthesis and Anti-Fungicidal Activity of Some Transition Metal Complexes with Benzimidazole Dithiocarbamate Ligand. Spectrochimica Acta Part A-Molecular and Biomolecular Spectroscopy. 72: 610-615.

[11] Leka Z B, Leovac V M, Lukic S, Sabo T J, Trifunovic S R, Szecsenyi K M (2006) Synthesis and Physico-Chemical Characterization of New Dithiocarabamato Ligand and Its Complexes with Copper(II), Nickel(II) and Palladium(II). Journal of Thermal Analysis and Calorimetry. 83: 687-691.

[12] Chauhan H, Bakshi A (2011) Synthetic, Spectroscopic, Thermal, and Structural Studies of Antimony(III) bis(pyrrolidinedithiocarbamato)alkyldithiocarbonates. Journal of Thermal Analysis and Calorimetry. 105: 937-946.

[13] Onwudiwe D C, Ajibade P A (2011) Synthesis, Characterization and Thermal Studies of $\mathrm{Zn}(\mathrm{II}), \mathrm{Cd}(\mathrm{II})$ and $\mathrm{Hg}$ (II) Complexes of N-Methyl-N-Phenyldithiocarbamate: The Single Crystal Structure of $\left[\left(\mathrm{C}_{6} \mathrm{H}_{5}\right)\left(\mathrm{CH}_{3}\right) \mathrm{NCS}_{2}\right]_{4} \mathrm{Hg}_{2}$. International Journal of Molecular Sciences. 12: 1964-1978.

[14] Onwudiwe D C, Ajibade P A, Omondi B (2011) Synthesis, Spectral and Thermal Studies of 2,2'-Bipyridyl Adducts of Bis(N-Alkyl-N-Phenyldithiocarbamato)Zinc(II). Journal of Molecular Structure. 987: 58-66.

[15] Wriedt M, Naether C (2011) Synthesis, Crystal Structures, Thermal and Magnetic Properties of New Selenocyanato Coordination Polymers with Pyrazine as Co-Ligand. Zeitschrift Fur Anorganische Und Allgemeine Chemie. 637: 666-671. 
[16] Köpf-Maier P, Klapötke T (1988) Antitumor Activity of Some Organomettalic Bismuth(III)Thiolates. Inorganica Chimica Acta. 152: 49-52.

[17] Cantos G, Barbieri C L, Iacomini M, Gorin P A J, Travassos L R (1993) Synthesis of Antimony Complexes of Yeast Mannan and Mannan Derivatives and Their Effect on Leishmania-Infected Macrophages. Biochemical Journal. 289: 155-160.

[18] Briand G G, Burford N (1999) Bismuth Compounds and Preparations with Biological or Medicinal Relevance. Chemical Reviews. 99: 2601-2658.

[19] Luan S R, Zhu Y H, Jia Y Q, Cao Q (2010) Characterization and Thermal Analysis of Thiourea and Bismuth Trichloride Complex. Journal of Thermal Analysis and Calorimetry. 99: 523-530.

[20] Zhong G Q, Luan S R, Wang P, Guo Y C, Chen Y R, Jia Y Q (2006) Synthesis, Characterization and Thermal Decomposition of Thiourea Complexes of Antimony and Bismuth Triiodide. Journal of Thermal Analysis and Calorimetry. 86: 775-781.

[21] Swain T (2012) Synthesis and Thermal Characterization of Sulfur Containing Methionine Bridged Cobalt(III) and Copper(II) Complex. Journal of Thermal Analysis and Calorimetry. 109: 365-372.

[22] Yang Q, Chen S, Gao S (2007) Syntheses and Thermal Properties of Some Complexes with 2-Mercaptonicotinic Acid. Journal of Thermal Analysis and Calorimetry. 90: 881885.

[23] Lee M L, Shi L P, Tian Y T, Gan C L, Miao X S (2008) Crystallization Behavior of Sb70Teз0 and $\mathrm{Ag}_{3} \mathrm{In}_{5} \mathrm{Sb}_{60} \mathrm{Te}_{22}$ Chalcogenide Materials for Optical Media Applications. Physica Status Solidi (a). 205: 340-344.

[24] Kotkata M F, Mansour S A (2011) Study of Glass Transition Kinetics of Selenium Matrix Alloyed with up to 10\% Indium. Journal of Thermal Analysis and Calorimetry. 103: 555561.

[25] Mehta N, Tiwari R S, Kumar A (2006) Glass Forming Ability and Thermal Stability of Some Se-Sb Glassy Alloys. Materials Research Bulletin. 41: 1664-1672.

[26] Bahishti A A, Majeed Khan M A, Patel B S, Al-Hazmi F S, Zulfequar M (2009) Effect of Laser Irradiation on Thermal and Optical Properties of Selenium-Tellurium Alloy. Journal of Non-Crystalline Solids. 355: 2314-2317.

[27] Ohto M, Itoh M, Tanaka K (1995) Optical and Electrical Properties of Ag-As-S Glasses. Journal of Applied Physics. 77: 1034-1039.

[28] Ogusu K, Kumagai T, Fujimori Y, Kitao M (2003) Thermal Analysis and Raman Scattering Study on Crystallization and Structure of $\operatorname{Ag}_{x}\left(A_{0.4 S e 0.6) 100-x}\right.$ Glasses. Journal of Non-Crystalline Solids. 324: 118-126.

[29] Saiter J M, Ledru J, Hamou A, Saffarini G (1998) Crystallization of AsxSe1-x from the Glassy State $(0.005<x<0.03)$. Physica B: Condensed Matter. 245: 256-262.

[30] Tonchev D, Fogal B, Belev G, Johanson R E, Kasap S O (2002) Properties of a-SbxSe1-x Photoconductors. Journal of Non-Crystalline Solids. 299-302, Part 2: 998-1001.

[31] Mikla V I, Mikhalko I P, Mikla V V (2001) Laser-Induced Amorphous-to-Crystalline Phase Transition in SbxSe1-x Alloys. Materials Science and Engineering: B. 83: 74-78. 
[32] Holubová J, Černošek Z, Černošková E (2009) The Selenium Based Chalcogenide Glasses with Low Content of As and Sb: DSC, Stepscan DSC and Raman Spectroscopy Study. Journal of Non-Crystalline Solids. 355: 2050-2053.

[33] Savage J A, Webber P J, Pitt A M (1978) An Assessment of Ge-Sb-Se Glasses as 8 to $12 \mu \mathrm{m}$ Infra-Red Optical Materials. Journal of Materials Science. 13: 859-864.

[34] Giridhar A, Narasimham P S L, Mahadevan S (1980) Electrical Properties of Ge-Sb-Se Glasses. Journal of Non-Crystalline Solids. 37: 165-179.

[35] Shaaban E, Tomsah I (2011) The Effect of Sb Content on Glass-Forming Ability, the Thermal Stability, and Crystallization of Ge-Se Chalcogenide Glass. Journal of Thermal Analysis and Calorimetry. 105: 191-198.

[36] Peng Q, Dong Y, Deng Z, Kou H, Gao S, Li Y (2002) Selective Synthesis and Magnetic Properties of $\alpha$-MnSe and MnSez Uniform Microcrystals. The Journal of Physical Chemistry B. 106: 9261-9265.

[37] Vlaev L T, Tavlieva M P (2007) Structural and Thermal Studies on the Solid Products in the System $\mathrm{MnSeO}_{3}-\mathrm{SeO}_{2}-\mathrm{H}_{2} \mathrm{O}$. Journal of Thermal Analysis and Calorimetry. 90: 385392.

[38] Vlaev L T, Genieva S D, Georgieva V G (2006) Study of the Crystallization Fields of Nickel(II) Selenites in the System $\mathrm{NiSeO}_{3}-\mathrm{SeO}_{2}-\mathrm{H}_{2} \mathrm{O}$. Journal of Thermal Analysis and Calorimetry. 86: 449-456.

[39] Gospodinov G G, Stancheva A G (2004) Physicochemical Study on Selenites of the Three-Component System $\mathrm{Yb}_{2} \mathrm{O}_{3}-\mathrm{SeO}_{2}-\mathrm{H}_{2} \mathrm{O}$. Journal of Thermal Analysis and Calorimetry. 76: 537-542.

[40] Dammak M, Khemakhem H, Mhiri T (2001) Superprotonic Conduction and Ferroelectricity in Addition Cesium Sulfate Tellurate $\mathrm{Cs}_{2} \mathrm{SO}_{4} \cdot \mathrm{Te}(\mathrm{OH})_{6}$. Journal of Physics and Chemistry of Solids. 62: 2069-2074.

[41] Dammak M, Khemakhem H, Mhiri T, Kolsi A W, Daoud A (1999) Structural and Vibrational Study of $\mathrm{K}_{2} \mathrm{SeO}_{4} \cdot \mathrm{Te}(\mathrm{OH})_{6}$ Material. Journal of Solid State Chemistry. 145: 612-618.

[42] Dammak M, Khemakhem H, Mhiri T, Kolsi A W, Daoud A (1998) Structure and Characterization of a Mixed Crystal $\mathrm{Rb}_{2} \mathrm{SO}_{4} \cdot \mathrm{Te}(\mathrm{OH})_{6}$. Journal of Alloys and Compounds. 280: 107-113.

[43] Abdelhedi M, Dammak M, Cousson A, Kolsi A W (2005) Structural, Calorimetric and Conductivity Study of the New Mixed Solution $\mathrm{Rb}_{2}\left(\mathrm{SO}_{4}\right)_{0.5}\left(\mathrm{SeO}_{4}\right)_{0.5} \mathrm{Te}(\mathrm{OH})_{6}$. Journal of Alloys and Compounds. 398: 55-61.

[44] Ktari L, Abdelhedi M, Bouhlel N, Dammak M, Cousson A (2009) Synthesis, Calorimetric, Structural and Conductivity Studies in a New Thallium Selenate Tellurate Adduct Compound. Materials Research Bulletin. 44: 1792-1796.

[45] Pansuriya P, Parekh H, Friedrich H, Maguire G (In Press) Bisthiourea: Thermal and Structural Investigation. Journal of Thermal Analysis and Calorimetry. DOI: 10.1007/s10973-012-2309-3.

[46] Ramamurthi K, Madhurambal G, Ravindran B, Mariappan M, Mojumdar S (2011) The Growth and Characterization of a Metal Organic Crystal, Potassium Thiourea Thiocyanide. Journal of Thermal Analysis and Calorimetry. 104: 943-947. 
[47] Rampon D S, Rodembusch F S, Schneider J M F M, Bechtold I H, Goncalves P F B, Merlo A A, Schneider P H (2010) Novel Selenoesters Fluorescent Liquid Crystalline Exhibiting a Rich Phase Polymorphism. Journal of Materials Chemistry. 20: 715-722.

[48] Xie Y, Zheng X, Jiang X, Lu J, Zhu L (2001) Sonochemical Synthesis and Mechanistic Study of Copper Selenides $\mathrm{Cu}_{2-x \mathrm{Se}} \beta$-CuSe, and $\mathrm{Cu}_{3} \mathrm{Se}$. Inorganic Chemistry. 41: 387392.

[49] Jiang Y, Xie B, Wu J, Yuan S, Wu Y, Huang H, Qian Y (2002) Room-Temperature Synthesis of Copper and Silver, Nanocrystalline Chalcogenides in Mixed Solvents. Journal of Solid State Chemistry. 167: 28-33.

[50] Chrissafis K, Paraskevopoulos K, Manolikas C (2006) Studying Cu2-xSe Phase Transformation through DSC Examination. Journal of Thermal Analysis and Calorimetry. 84: 195-199.

[51] Ribeiro da Silva M A V, Santos A F L O M, Gomes J R B, Roux M a V, Temprado M, Jiménez P, Notario R (2009) Thermochemistry of Bithiophenes and Thienyl Radicals. A Calorimetric and Computational Study. The Journal of Physical Chemistry A. 113: 11042-11050.

[52] Foces-Foces C, Roux M, Notario R, Segura M (2011) Thermal Behavior and Polymorphism in Medium-High Temperature Range of the Sulfur Containing Amino Acids L-Cysteine and L-Cystine. Journal of Thermal Analysis and Calorimetry. 105: 747756.

[53] Kerr K A, Ashmore J P (1973) Structure and Conformation of Orthorhombic L-Cysteine. Acta Crystallographica Section B. 29: 2124-2127.

[54] Gorbitz C H, Dalhus B (1996) L-Cysteine, Monoclinic Form, Redetermination at 120K. Acta Crystallographica Section C. 52: 1756-1759.

[55] Kolesov B A, Minkov V S, Boldyreva E V, Drebushchak T N (2008) Phase Transitions in the Crystals of L- and DL-Cysteine on Cooling: Intermolecular Hydrogen Bonds Distortions and the Side-Chain Motions of Thiol-Groups. 1. L-Cysteine. The Journal of Physical Chemistry B. 112: 12827-12839.

[56] Moggach S A, Allan D R, Clark S J, Gutmann M J, Parsons S, Pulham C R, Sawyer L (2006) High-Pressure Polymorphism in L-Cysteine: The Crystal Structures of LCysteine-III and L-Cysteine-IV. Acta Crystallographica Section B. 62: 296-309.

[57] Oughton B M, Harrison P M (1959) The Crystal Structure of Hexagonal L-Cystine. Acta Crystallographica. 12: 396-404.

[58] Chaney M O, Steinrauf L K (1974) The Crystal and Molecular Structure of Tetragonal LCystine. Acta Crystallographica Section B. 30: 711-716.

[59] Dahaoui S, Pichon-Pesme V, Howard J A K, Lecomte C (1999) Ccd Charge Density Study on Crystals with Large Unit Cell Parameters: The Case of Hexagonal L-Cystine. The Journal of Physical Chemistry A. 103: 6240-6250.

[60] Regis Botelho J, Duarte Gondim A, Garcia dos Santos I, Dunstan P, Souza A, Fernandes V, Araújo A (2004) Thermochemical Parameters of Dimethyl and Di-Iso-Propyl Dithiocarbamate Complexes of Palladium(II). Journal of Thermal Analysis and Calorimetry. 75: 607-613. 
[61] Airoldi C, Chagas A P (1992) Some Features of the Thermochemistry of CoordinationCompounds. Coordination Chemistry Reviews. 119: 29-65.

[62] de Souza A, Neto F, de Souza J, Macedo R, de Oliveira J, Pinheiro C (1997) Thermochemical Parameters of Complexes of Di-Isobutyldithiocarbamate with Phosphorus-Group Elements. Journal of Thermal Analysis and Calorimetry. 49: 679684.

[63] Feng M-L, Xie Z-L, Huang X-Y (2009) Two Gallium Antimony Sulfides Built on a Novel Heterometallic Cluster. Inorganic Chemistry. 48: 3904-3906.

[64] Yao H-G, Ji M, Ji S-H, Zhang R-C, An Y-L, Ning G-l (2009) Solvothermal Syntheses of Two Novel Layered Quaternary Silver-Antimony(III) Sulfides with Different Strategies. Crystal Growth \& Design. 9: 3821-3824.

[65] Ribeiro da Silva M A V, Santos A F L O M (2010) Thermochemical Properties of Two Nitrothiophene Derivatives 2-Acetyl-5-Nitrothiophene and 5-Nitro-2Thiophenecarboxaldehyde. Journal of Thermal Analysis and Calorimetry. 100: 403-411.

[66] Morais C, Pat B, Gobe G, Johnson D W, Healy H (2006) Pyrrolidine Dithiocarbamate Exerts Anti-Proliferative and Pro-Apoptotic Effects in Renal Cell Carcinoma Cell Lines. Nephrology Dialysis Transplantation. 21: 3377-3388.

[67] Morais C, Gobe G, Johnson D W, Healy H (2009) Anti-Angiogenic Actions of Pyrrolidine Dithiocarbamate, a Nuclear Factor Kappa B Inhibitor. Angiogenesis. 12: 365-379.

[68] Kostova I (2006) Platinum Complexes as Anticancer Agents. Recent Patents on AntiCancer Drug Discovery. 1: 1-22.

[69] Yao X, Panichpisal K, Kurtzman N, Nugent K (2007) Cisplatin Nephrotoxicity: A Review. American Journal of the Medical Sciences. 334: 115-124.

[70] Galanski M, Arion V B, Jakupec M A, Keppler B K (2003) Recent Developments in the Field of Tumor-Inhibiting Metal Complexes. Current Pharmaceutical Design. 9: 20782089.

[71] Jones M M, Basinger M A, Mitchell W M, Bradley C A (1986) Inhibition of CisDiamminedichloroplatinum(II)-Induced Renal Toxicity in the Rat. Cancer Chemotherapy and Pharmacology. 17: 38-42.

[72] Gandara D R, Wiebe V J, Perez E A, Makuch R W, Degregorio M W (1990) Cisplatin Rescue Therapy - Experience with Sodium Thiosulfate, WR2721, and Diethyldithiocarbamate. Critical Reviews in Oncology/Hematology. 10: 353-365.

[73] Hidaka S, Tsuruoka M, Funakoshi T, Shimada H, Kiyozumi M, Kojima S (1994) Protective Effects of Dithiocarbamates against Renal Toxicity of CisDiamminedichloroplatinum in Rats. Renal Failure. 16: 337-349.

[74] Botelho J R, Gondim A D, Santos I M G, Dunstan P O, Souza A G, Fernandes V J, Araujo A S (2004) Thermochemical Parameters of Dimethyl and Di-Iso-Propyl Dithiocarbamate Complexes of Palladium(II). Journal of Thermal Analysis and Calorimetry. 75: 607-613.

[75] Botelho J, Souza A, Nunes L, Chagas A, Garcia dos Santos I, da Conceição M, Dunstan P (2002) Thermochemical Properties of Palladium(II) Chelates Involving Dialkyldithiocarbamates. Journal of Thermal Analysis and Calorimetry. 67: 413-417. 
[76] Fregona D, Giovagnini L, Ronconi L, Marzano C, Trevisan A, Sitran S, Biondi B, Bordin F (2003) Pt(II) and Pd(II) Derivatives of Ter-Butylsarcosinedithiocarbamate. Synthesis, Chemical and Biological Characterization and in Vitro Nephrotoxicity. Journal of Inorganic Biochemistry. 93: 181-189.

[77] Giovagnini L, Marzano C, Bettio F, Fregona D (2005) Mixed Complexes of Pt(II) and $\operatorname{Pd}(\mathrm{II})$ with Ethylsarcosinedithiocarbamate and 2-/3-Picoline as Antitumor Agents. Journal of Inorganic Biochemistry. 99: 2139-2150.

[78] Faraglia G, Fregona D, Sitran S, Giovagnini L, Marzano C, Baccichetti F, Casellato U, Graziani R (2001) Platinum(II) and Palladium(II) Complexes with Dithiocarbamates and Amines: Synthesis, Characterization and Cell Assay. Journal of Inorganic Biochemistry. 83: 31-40.

[79] Manav N, Mishra A K, Kaushik N K (2006) In Vitro Antitumour and Antibacterial Studies of Some $\mathrm{Pt}(\mathrm{IV})$ Dithiocarbamate Complexes. Spectrochimica Acta Part AMolecular and Biomolecular Spectroscopy. 65: 32-35.

[80] Manav N, Mishra A K, Kaushik N K (2004) Triphenyl Phosphine Adducts of Platinum(IV) and Palladium(II) Dithiocarbamates Complexes: A Spectral and in Vitro Study. Spectrochimica Acta Part A-Molecular and Biomolecular Spectroscopy. 60: 30873092.

[81] Uivarosi V, Badea M, Aldea V, Chirigiu L, Olar R (In Press) Thermal and Spectral Studies of Palladium(II) and Platinum(IV) Complexes with Dithiocarbamate Derivatives. Journal of Thermal Analysis and Calorimetry.

[82] Rademaker-Lakhai J M, van den Bongard D, Pluim D, Beijnen J H, Schellens J H M (2004) A Phase I and Pharmacological Study with Imidazolium-Trans-Dmso-ImidazoleTetrachlororuthenate, a Novel Ruthenium Anticancer Agent. Clinical Cancer Research. 10: 3717-3727.

[83] Alessio E, Mestroni G, Nardin G, Attia W M, Calligaris M, Sava G, Zorzet S (1988) CisDihalotetrakis(Dimethyl Sulfoxide)Ruthenium(II) and Trans-Dihalotetrakis(Dimethyl Sulfoxide)Ruthenium(II) Complexes ( $\left.\mathrm{RuX}_{2}(\mathrm{Dmso})_{4}, \mathrm{X}=\mathrm{Cl}, \mathrm{Br}\right)$ - Synthesis, Structure, and Antitumor-Activity. Inorganic Chemistry. 27: 4099-4106.

[84] Alessio E, Iengo E, Geremia S, Calligaris M (2003) New Geometrical and Linkage Isomers of the $\mathrm{Ru}(\mathrm{II})$ Precursor Cis,Cis,Trans-RuCl$\left(\mathrm{Dmso}_{2}\right)_{2}(\mathrm{Dmso}-\mathrm{O})(\mathrm{CO})$ : $\mathrm{A}$ Spectroscopic and Structural Investigation. Inorganica Chimica Acta. 344: 183-189.

[85] Zhelev Z, Ohba H, Bakalova R, Hadjimitova V, Ishikawa M, Shinohara Y, Baba Y (2004) Phenothiazines Suppress Proliferation and Induce Apoptosis in Cultured Leukemic Cells without Any Influence on the Viability of Normal Lymphocytes - Phenothiazines and Leukemia. Cancer Chemotherapy and Pharmacology. 53: 267-275.

[86] Hollo B, Krstic M, Sovilj S P, Pokol G, Szecsenyi K M (2011) Thermal Decomposition of New Ruthenium(II) Complexes Containing N-Alkylphenothiazines. Journal of Thermal Analysis and Calorimetry. 105: 27-32.

[87] Plano D, Sanmartin C, Moreno E, Prior C, Calvo A, Palop J A (2007) Novel Potent Organoselenium Compounds as Cytotoxic Agents in Prostate Cancer Cells. Bioorganic \& Medicinal Chemistry Letters. 17: 6853-6859. 
[88] Plano D, Baquedano Y, Ibáñez E, Jiménez I, Palop J A, Spallholz J E, Sanmartín C (2010) Antioxidant-Prooxidant Properties of a New Organoselenium Compound Library. Molecules. 15: 7292-7312.

[89] Ibáñez E, Plano D, Font M, Calvo A, Prior C, Palop J A, Sanmartín C (2011) Synthesis and Antiproliferative Activity of Novel Symmetrical Alkylthio- and AlkylselenoImidocarbamates. European Journal of Medicinal Chemistry. 46: 265-274.

[90] Ibáñez E, Agliano A, Prior C, Nguewa P, Redrado M, González-Zubeldia I, Plano D, Palop J A, Sanmartin C, Calvo A (2012) The Quinoline Imidoselenocarbamate EI201 Blocks the Akt/Mtor Pathway and Targets Cancer Stem Cells Leading to a Strong Antitumor Activity. Current Medicinal Chemistry. 19: 3031-3043.

[91] Plano D, Lizarraga E, Font M, Palop J A, Sanmartin C (2009) Thermal Stability and Decomposition of Sulphur and Selenium Compounds. Journal of Thermal Analysis and Calorimetry. 98: 559-566.

[92] Kitamura S, Miyamae A, Koda S, Morimoto Y (1989) Effect of Grinding on the SolidState Stability of Cefixime Trihydrate. International Journal of Pharmaceutics. 56: 125134.

[93] Perrenot B, Widmann G (1994) Polymorphism by Differential Scanning Calorimetry. Thermochimica Acta. 234: 31-39.

[94] Plano D, Lizarraga E, Palop J, Sanmartín C (2011) Study of Polymorphism of Organosulfur and Organoselenium Compounds. Journal of Thermal Analysis and Calorimetry. 105: 1007-1013.

[95] Sanmartin C, Plano D, Dominguez E, Font M, Calvo A, Prior C, Encio I, Palop J A (2009) Synthesis and Pharmacological Screening of Several Aroyl and Heteroaroyl Selenylacetic Acid Derivatives as Cytotoxic and Antiproliferative Agents. Molecules. 14: 3313-3338. 